\title{
Um Percurso de Estudo e Pesquisa para o Estudo das Noções de Juros Simples e Compostos
}

\section{A Study and Research Path for the Study of Simple and Compound Interest}

\author{
Notions
}

\author{
Valdir Bezerra dos Santos Júnior* \\ ORCID iD 0000-0002-3869-201X \\ Marlene Alves Dias** \\ ORCID iD 0000-0001-9168-9066 \\ Marianna Bosch*** \\ ORCID iD 0000-0001-9756-116X
}

\begin{abstract}
Resumo
Neste artigo, apresentamos um recorte de um estudo sobre as relações pessoais de um grupo de estudantes do Ensino Superior de Tecnologia em Gestão Comercial, submetidos a um Percurso de Estudo e Pesquisa - PEP. Focamos aqui no processo de implementação e experimentação do PEP e a análise dos gestos didáticos encontrados durante este processo. Sendo a engenharia didática de tipo PEP um constructo teórico da Teoria Antropológica do Didático - TAD, consideramos aqui elementos dessa teoria que fundamentaram teoricamente a pesquisa, em particular, as noções relação pessoal, praxeologia e as dialéticas. A pesquisa foi de natureza qualitativa e a experimentação do PEP foi realizada com noventa estudantes de uma universidade particular do estado de São Paulo em oito sessões de uma hora cada. Como resultado, observamos que, em função da nova metodologia utilizada, as noções do domínio da Matemática Financeira foram tratadas pelos estudantes como ferramentas integradas a outras disciplinas, o que não corresponde à forma de desenvolvimento habitual do curso.
\end{abstract}

Palavras-chave: Percurso de Estudo e Pesquisa. Relação Pessoal. Matemática Financeira.

\begin{abstract}
In this paper, we present a study of the personal relations of a group of higher education business management technology students submitted to a Study and Research Path - SRP. We focused on the SRP implementation and experimentation process and the analysis of didactic gestures found during this process. As the didactic engineering

* Doutor em Educação Matemática pela Universidade Anhanguera de São Paulo (UNIAN). Professor da Universidade Federal de Pernambuco (UFPE), Caruaru, Pernambuco, Brasil. Endereço para correspondência: Avenida Manoel Borba, 738, apt. 1102, Boa Vista, Recife, Pernambuco, Brasil, CEP: 50070-000. E-mail: valdir.bezerra@gmail.com.

** Doutora em Matemática pela Universidade Dennis Diderot - Paris 7, França. Professora do Programa de Pósgraduação da Universidade Anhanguera de São Paulo (UNIAN), São Paulo, Brasil. Endereço para correspondência: Rua Sobralia, 407, São Paulo, São Paulo, Brasil, CEP: 04691-020. E-mail: maralvesdias@gmail.com.

*** Doutora em Matemática pela Universidade Autônoma de Barcelona (UAB). Professora Catedrática de IQS School of Management da Universidade Ramon Llull, Barcelona, Espanha. Endereço para correspondência: Via Augusta 390, 08017, Barcelona, Espanha. E-mail mariannabosch@gmail.com.
\end{abstract}


of SRPs is a theoretical construct of the Anthropological Theory of the Didactic - ATD, we consider here the elements of this theory that theoretically grounded the research, in particular, the notions of personal relation, praxeologies, and the inquiry dialectics. The research was of a qualitative nature and the SRP experimentation was carried out with ninety students from a private university of the state of São Paulo in eight one-hour sessions. We observed that, as a result of the new methodology used, the notions of the financial mathematics field were treated by the students as tools integrated to other disciplines, which does not correspond to the usual development of the course.

Keywords: Study and Research Path. Personal Relation. Financial Mathematics.

\section{Introdução}

Este trabalho é um recorte de pesquisa desenvolvida em tese de doutorado. A motivação da pesquisa advém de experiências na docência no Ensino Superior de Tecnologia, mais conhecido como curso tecnológico para a formação de tecnólogos de nível superior.

A experiência lecionando nos cursos tecnológicos da área de Gestão e Negócio, em especial na disciplina de Matemática Financeira - MF, possibilitou a reflexão sobre a existência de material didático, em particular, livros de Matemática Financeira que auxiliassem a abordar a MF de maneira a dar sentido de se trabalhar este domínio com os futuros tecnólogos em Logística, Gestão de Pessoas, Gestão Hospitalar etc. Como docente dos cursos tecnólogos, verificamos que as abordagens realizadas nos livros de MF não correspondiam à realidade do campo de trabalho (Gestão e Negócios), pois continham ênfase matemática, ou seja, centrada na aplicação de fórmulas e algoritmos.

Diante dessa constatação, construímos o questionamento para a pesquisa: Como desenvolver atividades relacionadas às necessidades dos profissionais dos cursos superiores de tecnologia, na área de Gestão e Negócios, no ensino das noções de juros simples e compostos? Note-se a redução do campo de estudo aos setores juros simples e compostos.

Partimos do pressuposto de que, para responder ao questionamento, precisamos realizar uma análise ecológica e econômica (CHEVALLARD, 2011). Ecológica no sentido de compreender como os saberes juros simples e compostos vivem e sobrevivem nas instituições das quais eles fazem parte e econômica no sentido de entender o que é preciso fazer para que um estudante da área de Gestão e Negócios aprenda juros simples e compostos.

Focamos aqui na perspectiva econômica, em especial, com o olhar na utilização da organização didática proposta por Chevallard (2007) denominada Percurso de Estudo e Pesquisa - PEP. Para o desenvolvimento do PEP, fomos conduzidos a formular as seguintes questões: Qual é a relação pessoal dos estudantes dos cursos superiores de tecnologia da área de Gestão e Negócios com as noções de juros simples e compostos submetidos a um PEP? 
Como se dá o desenvolvimento da aplicação de um Percurso de Estudo e Pesquisa? Assim, o objetivo da pesquisa foi: analisar as relações pessoais dos estudantes do curso superior de tecnologia, na área de Gestão e Negócios, em relação às noções de juros simples e compostos submetidos a um Percurso de Estudo e Pesquisa.

Para atingir nosso objetivo, consideramos o trabalho de Chevallard (2007), que adverte para o fato de que o ensino da disciplina de Matemática mostra-se distante da realidade do estudante e com isso perde o sentido, o que se deve ao movimento que ocorre, principalmente na escola, denominado pelo autor de monumentalismo dos saberes. Compara-se a uma visita ao museu, quando uma pessoa, guia ou equipamento eletrônico apresenta as obras sem questionar sua importância ou utilidade para o visitante. Analogamente tem-se a apresentação das temáticas ligadas à disciplina de Matemática na escola, as quais visitamos com deferência, como monumentos que perderam sua funcionalidade, e que, segundo o autor, têm apenas raros empregos danosos, oportunistas e minúsculos. Uma homenagem apenas formal.

Para Chevallard (2007), é preciso refletir sobre o papel das temáticas abordadas em sala de aula, citando como exemplo o estudo do triângulo na Educação Básica a partir das questões: "Mas qual questão Matemática gera o interesse dos matemáticos pelo triângulo? E por que continuamos a estudar os triângulos na escola?" (CHEVALLARD, 2007, p. 22, grifo do autor). Estas questões, conforme o autor, apontam que temos esquecido de considerá-las para os saberes a ensinar e continuamos assim tratando teoricamente as propriedades dos triângulos, por exemplo, que indicam que as medianas, as alturas, as bissetrizes são concorrentes, sem nos preocupar com seu emprego (CHEVALLARD, 2007).

Pensando no estudo do triângulo, podemos questionar também as noções associadas ao domínio da Matemática Financeira: por que continuamos a estudar juros simples e compostos na escola? Ou especificamente para este trabalho: por que estudamos juros simples e compostos num curso superior de tecnologia da área de Gestão e Negócios? Essa resposta não é encontrada, atualmente, nos documentos que norteiam o Ensino Superior de tecnologia.

Acreditamos que a busca pela resposta da razão de ser dos conteúdos presentes nos programas escolares e/ou universitários ajuda na proposição de mudanças, as quais devem interferir na organização atual da escola, que precisa mudar de paradigma, podendo passar ao questionamento do mundo em contraponto ao monumentalismo da visita às obras.

Esse novo paradigma diferencia-se, porque a consulta às obras não é o fim, mas o meio. A busca pelas respostas não é uma simples busca pela informação, mas um momento de construção e reconstrução de conhecimentos, uma situação de pesquisa e de questionamentos. Chevallard (2007) propõe a utilização de uma organização didática associada diretamente às 
ações na sala de aula, o PEP. Sua característica principal é partir de um questionamento $\left(\mathrm{Q}_{0}\right)$, pois $\mathrm{Q}_{0}$ é uma questão com poder gerador de novas questões de modo a criar um ambiente de estudo e pesquisa. Na sequência, explicitamos como se configura o PEP.

\section{A organização didática: Percurso de Estudo e Pesquisa}

Iniciamos esta seção indicando alguns PEP experimentados na Espanha, França e Portugal. Observamos em artigos e teses os domínios matemáticos contemplados nestas experimentações, a saber: Geometria (MATHERON; NOIRFALISE, 2007), Função (RODRÍGUEZ, BOSCH, GASCÓN, 2007; BARQUERO, BOSCH, GASCÓN, 2007; BARQUERO, BOSCH, GASCÓN, 2011), Álgebra (RUIZ, BOSCH, GASCÓN, 2007; BOSCH, 2010), Cálculo Diferencial e Integral (SERRANO, BOSCH, GASCÓN, 2007; LUCAS, 2015). Em comum nos trabalhos há a presença de uma questão Q 0 geradora do ambiente de estudo e pesquisa para o desenvolvimento do PEP.

Para explicitar um PEP, é preciso compreender a noção de sistema didático na perspectiva da TAD. Para Chevallard (2011), um sistema didático $S(X, Y, \boldsymbol{\vee})$ pode ser uma instância representada por um grupo de estudantes, indicado por $X$, cujos membros são indicados por x, com uma instância de ajuda indicada por $Y$; seus membros são indicados por y e um desafio didático $\bullet$, que é uma obra a ser estudada por $X$ com a ajuda de $Y$.

Num sistema didático, no qual o PEP está inserido, o desafio didático é uma questão $Q_{0}$ geradora de novos questionamentos e de respostas, ou seja, $S(X, Y, Q)$. No PEP aqui desenvolvido, o sistema didático correspondente foi: $X$ o conjunto de estudantes de um curso superior de Tecnologia de Gestão Comercial, y é o pesquisador que desenvolveu a pesquisa e o desafio didático, a questão inicial $Q_{0}$ : Como decidir o tipo de empréstimo para uma empresa?

Ressaltamos que a busca para responder ao questionamento $\mathrm{Q}_{0}$ é o norte do trabalho do sistema didático. Para isso, é preciso desenvolver um meio $M$ formado por um conjunto de recursos velhos e novos, que serão utilizados por $X$. Este meio $M$ é composto de questões derivadas de $Q_{0}$, de respostas já "prontas" em relação a $Q_{0}$, validadas por uma ou mais instituições, nomeadas de $R^{\diamond}$ (R punção). A análise das respostas $R^{\diamond}$ fornece elementos para a construção da resposta $R^{\vee}$ (R coração). Outros elementos que compõem o meio $M$ e ainda fornecem ferramentas para análise das respostas $R^{\diamond}$ são as obras $O$ da cultura e os dados coletados $D$, uma vez que, segundo Chevallard (2016), no PEP são tratadas todas as questões umbilicais que possam aparecer quando do estudo da questão inicial $Q_{0}$ (CHEVALLARD, 2016). 
Simbolicamente, podemos compreender o sistema didático no qual o desafio didático é responder a um questionamento $Q_{0}$ da seguinte forma:

$\left[S(X ; Y ; Q) \rightarrow\left\{Q_{1} Q_{2}, \ldots, O_{m}, R_{m+1}^{\diamond}, R_{m+2}^{\diamond_{2}}, \ldots, R_{n}^{\diamond_{n}}, O_{n+1}, \ldots, O_{p}, D_{p+1}, \ldots, D_{q}\right\}\right] \Rightarrow R^{\diamond}$ (esquema herbatiano).

Importante ressaltar que $R^{\vee}$ não é uma resposta previamente estabelecida pela instância de ajuda Y. Assim, para as possíveis respostas $R^{\natural}$, a instância $Y$ de ajuda pode até realizar uma análise a priori de possíveis respostas $\mathrm{R}^{\diamond}$ e caminhos a serem seguidos na busca pela resposta $R^{\boldsymbol{\vartheta}}$ (isso ajuda a compreender o poder gerador da questão $Q_{0}$, pois mostra as possíveis respostas e novos questionamentos); todavia os gestos de estudo e pesquisa realizados pelos estudantes de $X$ podem levar ou não a questionamentos e respostas inseridos no que foi analisado a priori. Podemos afirmar que os gestos de estudo e pesquisa que compõem um sistema didático $S(X, y$, $Q)$ são: “observar, analisar, avaliar as respostas $R^{\diamond}$ disponíveis na cultura, e, usando algumas obras O, desenvolver e depois defender e ilustrar uma resposta $R^{\boldsymbol{\nu} "}$ (CHENEVEZ, 2008, p. 17).

Em relação à análise a priori que pode ser feita em relação à questão $Q_{0}$, podemos verificar na Figura 1 possíveis caminhos que os estudantes do nosso sistema didático poderiam percorrer na construção da resposta $R^{\vee}$.

Veremos na parte dedicada à análise do PEP que os caminhos seguidos pelos estudantes abordaram questões e respostas não previstas.

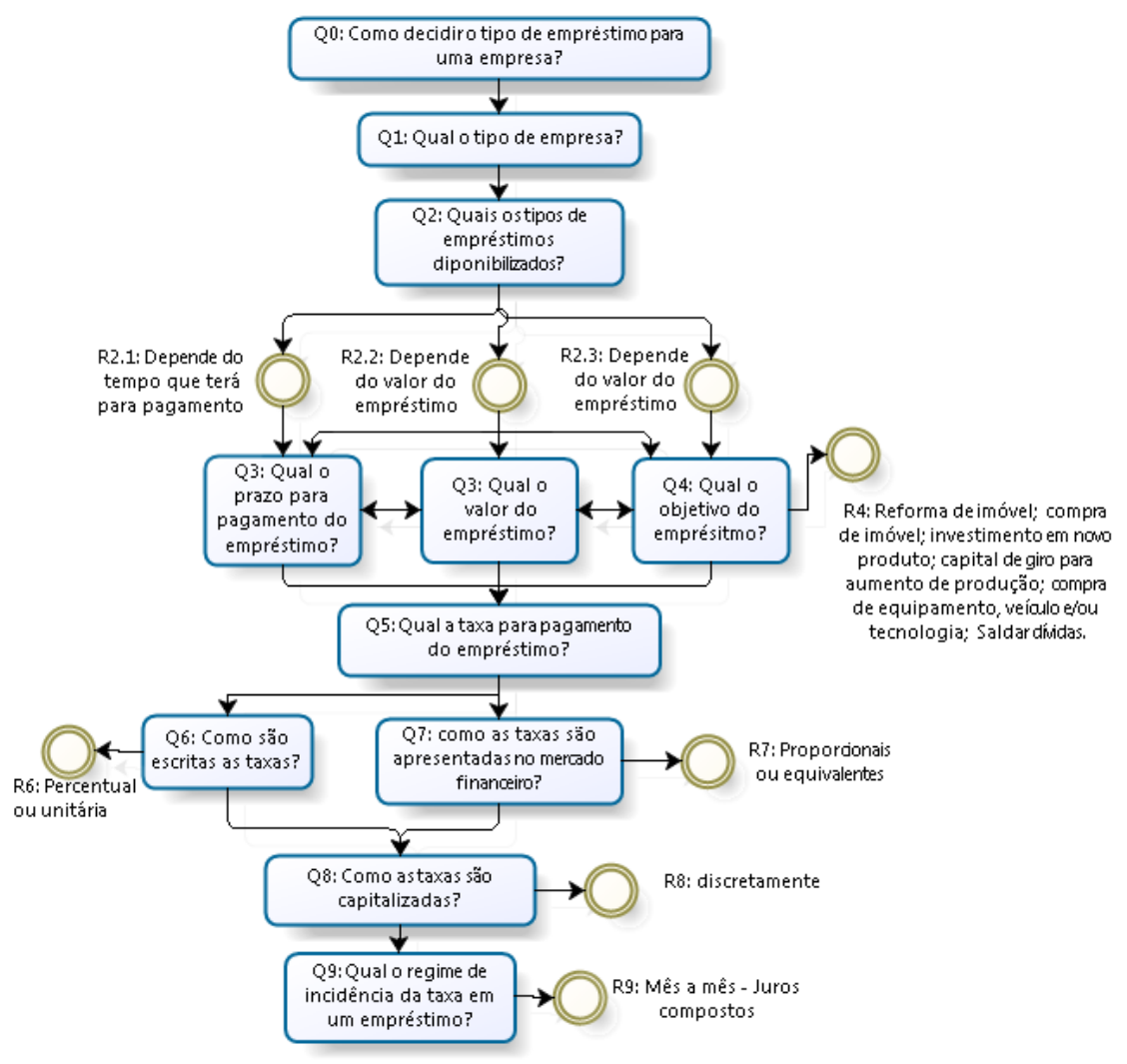


Figura 1 - Percurso de Estudo e Pesquisa Fonte: $\mathrm{O}$ autor (2017)

A análise a priori foi feita em paralelo com a construção de um modelo epistemológico de referência - MER, que serve como instrumento para análise e projeto didático do PEP. Na visão de Bosch e Gascón (2010), o MER deve ser considerado como sistema de referência relativo e transitório. Desse modo, o MER logo pode passar por modificações que dependem do caminho escolhido pelos estudantes, o que indica a possibilidade de aparecerem caminhos não previstos, que precisam ser inseridos no MER. Os autores assim o justificam:

[...] temos utilizado, em cada caso, como instrumento de análise do modelo epistemológico das matemáticas dominantes na instituição escolar e como auxiliares para caracterizar os modelos docentes espontâneos que se sustentam no citado modelo epistemológico (BOSCH e GASCÓN, 2010, p.61 - tradução nossa).

Norteando-nos pelas ideias de Sierra (2006) e Lucas (2015), construímos um mapa com as organizações matemáticas e suas interligações, em específico, do domínio da Matemática Financeira, pois tratamos na pesquisa dos setores juros simples e compostos (Ver Figura 2). As organizações matemáticas foram identificadas a partir do estudo das obras (livros de Matemática Financeira dos países: Brasil, Espanha, Estados Unidos e Inglaterra), buscando interligar as noções intra ou extramatemáticas do domínio da Matemática Financeira.

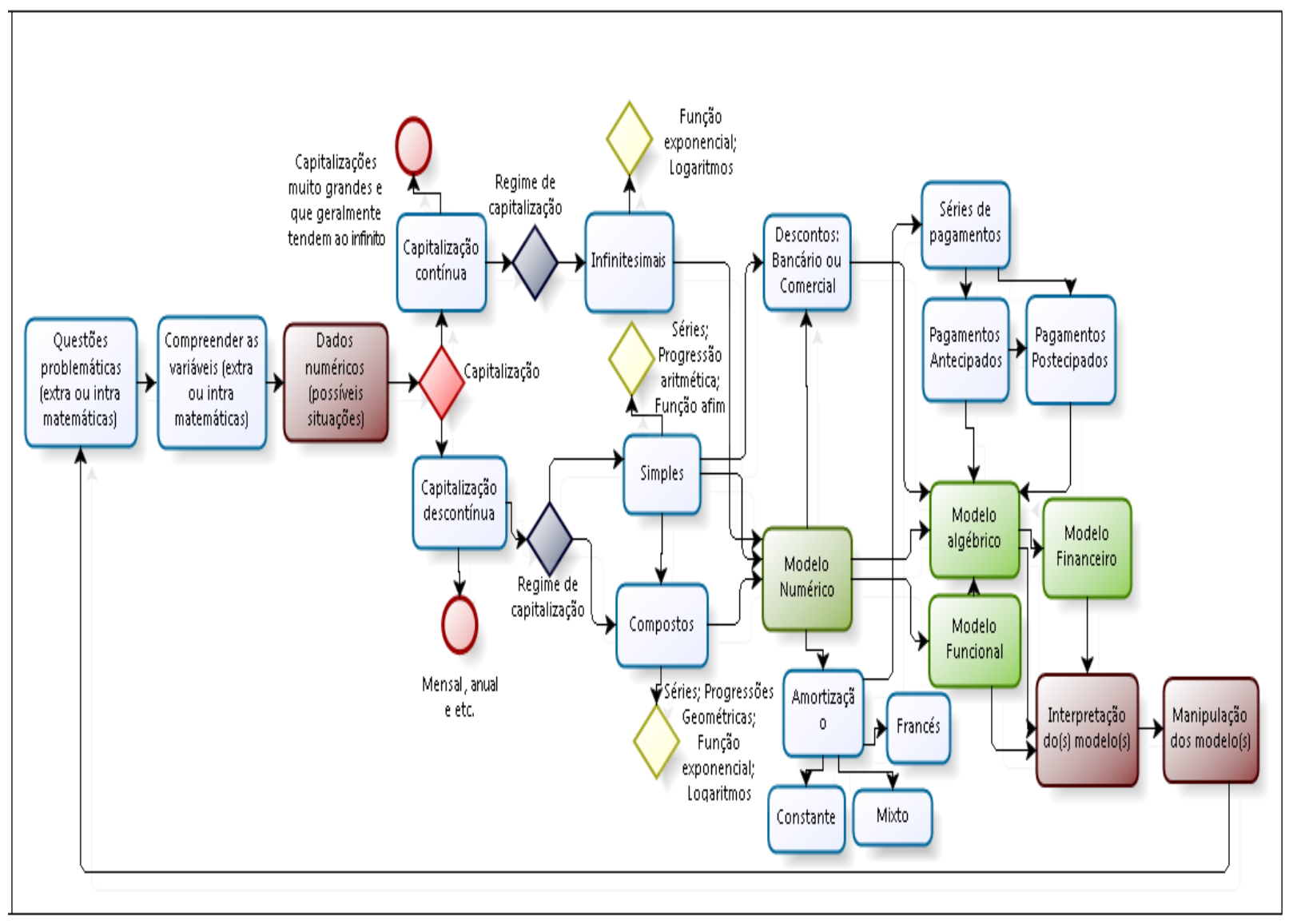

Figura 2 - Modelo Epistemológico de Referência Fonte: O autor (2017) 
No MER, partimos da conjectura que o domínio da Matemática Financeira pode ser ensinado a partir de questões geradoras, como a que propusemos no PEP. A partir deste tipo de questões, é preciso compreender as variáveis a estudá-las na busca de resposta para o questionamento, que podem ser intra ou extramatemáticas. Na sequência, inicia-se o estudo dos dados numéricos fornecidos ou designados pelo sistema didático, os quais proporcionam tomar decisões sobre temas e setores pertencentes ao domínio da Matemática Financeira, representados por balões de contorno azul. Destacamos nos losangos de contorno amarelo temas e setores da disciplina Matemática, associados ao domínio da Matemática Financeira.

Os losangos com contorno em azul marinho correspondem a caminhos a serem seguidos de acordo com o tema e setor que estão interligados. Nos círculos com o contorno vermelho, estão algumas respostas para o que é tratado nos balões de contorno azul. Ainda temos os balões em cor vermelha, que abrangem possibilidades de ações desenvolvidas na tentativa de responder ao questionamento, e verdes, que são os ostensivos a serem manipulados na resolução do problema. As setas no mapa não correspondem ao sentido que as situações ocorrem, mas aquele que pode ocorrer.

Um resultado da construção do MER em paralelo à construção do PEP é observar que o domínio da Matemática Financeira pode ser estudado por meio de diferentes caminhos; aqui consideramos quatro modelos: funcional, numérico, algébrico e financeiro.

\section{Aspectos teóricos da Teoria Antropológica do Didático}

Respaldadas teoricamente pela TAD, algumas noções deste estudo servem como ferramentas para alcançar o objetivo de pesquisa. As essenciais para a compreensão deste artigo são: relação pessoal, praxeologia e as dialéticas mídia-meio, questão-resposta e individual-coletivo.

Chevallard (2001, 2002), após considerar os elementos primitivos: objeto $o$, instituição $I$ e pessoa $x$ e indicar que a TAD é uma teoria quase axiomática, define relação pessoal com $o$ toda relação que um indivíduo $x$ tem com um objeto $o$, indicada $R(x, o)$. Um exemplo de relação pessoal corresponde à situação que habitualmente está associada ao ensino de álgebra elementar na Educação Básica. Os estudantes, até serem apresentados à utilização de álgebra para a resolução de problemas, têm uma relação pessoal com as letras do alfabeto, que serviam para construir textos, realizar leituras etc. Ao serem apresentados à outra "utilidade" das letras, que se distancia da disciplina de Português, inserindo-se numa nova disciplina, a Matemática, temse a nova relação desses estudantes com as letras do alfabeto. 
$\mathrm{Na}$ nossa pesquisa, investigamos a relação pessoal dos indivíduos de um grupo de estudantes que se propuseram a participar da pesquisa por meio de um PEP, o que pode tê-los conduzido ao aprendizado de novas organizações matemáticas e/ou extramatemáticas.

Aqui, a palavra organização não é arbitrária, pois neste texto ela está associada à noção de praxeologia. Para Chevallard (2001), toda atividade humana pode ser descrita em termo de praxeologia definida pela quádrupla: tipo de tarefas $T$; ao menos uma técnica $\tau$ para resolver o tipo de tarefas $T$; tecnologia $\theta$, que torna compreensível e justifica a técnica utilizada; e a teoria $\Theta$, que justifica a tecnologia, representada por $[T, \tau, \theta, \Theta]$

No domínio da Matemática Financeira, podemos considerar como exemplo: Calcule o montante de um capital de $\mathrm{R} \$ 10.000,00$ aplicados a uma taxa de $1 \%$ ao mês, durante 12 meses e capitalizado no regime de juros compostos. Nesta atividade, o tipo de tarefas é: calcular o montante com regime de capitalização exponencial; como possível técnica: utilizar a fórmula $\mathrm{M}=\mathrm{C}(1+\mathrm{i})^{\mathrm{t}}$, como tecnologia, a noção de equação e equação exponencial e a noção de operações e propriedades dos números reais; e a teoria dos juros compostos.

Outras noções associadas à TAD que surgem dos gestos didáticos no sistema didático PEP são: as dialéticas mídia-meio, questão-resposta e individual-coletivo, que servem de ferramenta de análise para compreender as vivências e o desenvolvimento de um PEP.

Conforme Chevallard (2008), a busca pela resposta $R^{\boldsymbol{\nu}}$ evidencia a dialética mídia-meio na medida em que as respostas $R_{i}^{\diamond}$ são consultadas em meios de comunicação e difusão (mídias), mas as respostas encontradas sofrem desconstruções e reconstruções, logo precisam de instrumentos (meios) para validá-las na busca pela resposta a $Q_{0}$ “"A dialética mídia-meio corresponde à contínua interação entre respostas disponíveis (parciais) fornecidas pela mídia e seus testes por meio da interação com um meio adidático" (KIDRON et al., 2014, p. 158, tradução nossa). Um meio adidático à luz da teoria das situações didáticas (BROUSSEAU, 1998) é aquele que contempla o modo como se configura o esquema herbatiano, mesmo que no caso do último, a busca pela resposta a $Q_{0}$ não seja apenas da responsabilidade dos estudantes $X$, mas representa um trabalho conjunto dos atores X e Y (KIDRON et al., 2014). Em relação à

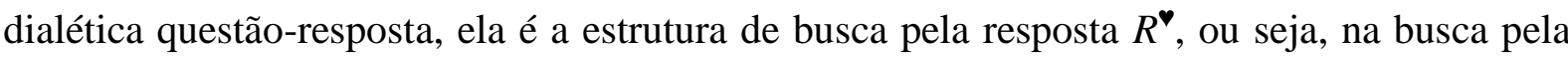
resposta a $Q_{0}$, encontram-se respostas $R_{i}^{\diamond}$ institucionalmente validadas e que sofrem desconstruções e reconstruções, resultando em novos questionamentos que ampliam a busca pela resposta $R^{\vee}$ (HAUSBERGER, 2016). Podemos afirmar brevemente que esta dialética interfere diretamente no tempo didático de uma situação de ensino, o que vamos observar por meio da análise do PEP proposto na pesquisa. 
Por fim, temos a dialética individual-coletivo que corresponde à divisão das responsabilidades dos atores no processo de estudo, ou seja, como as responsabilidades na busca pela resposta $R^{\vee}$ são divididas entre os próprios estudantes e o professor. Pode-se considerar também o cenário no qual as responsabilidades são distribuídas em grupos e esses grupos se complementam e se modificam, quando da interação na exposição das possíveis respostas para $\mathrm{Q}_{0}$ (BARQUERO et al., 2016).

\section{Desenho metodológico}

O sistema didático no qual esta pesquisa se insere é composto por 90 estudantes de um curso superior de Tecnologia em Gestão Comercial de uma universidade particular do estado de São Paulo. O professor é o próprio pesquisador e o desafio didático consiste em responder ao questionamento: $Q_{0}$ : Como decidir o tipo de empréstimo para uma empresa? Ou seja, a questão inicial ou geradora de outras questões, como por exemplo, as apresentadas anteriormente por meio do MER.

Observamos aqui que a metodologia para o desenvolvimento da pesquisa foi a da engenharia didática de tipo PEP, que corresponde a propor uma questão inicial ampla o suficiente para gerar novas questões, isto é, diferentes caminhos que permitem tratar a questão inicial para encontrar uma resposta.

Para a realização da pesquisa, foram previstas quinze sessões, mas é importante ressaltar que as intervenções foram realizadas durante oito sessões de uma hora cada, no mesmo horário em que ocorriam as aulas (noturno), o que difere do programado, em razão de feriados e outras interferências. Conseguimos este espaço junto ao professor da disciplina Matemática Financeira, após explicar o que realizaríamos e que estava diretamente ligado a sua disciplina. Esse docente nunca se ausentou da sala no período em que assumimos a classe e sempre esteve disposto a ajudar.

Em relação aos 90 estudantes, destacamos que nem todos participaram de todas as oito sessões. Este número reflete o quantitativo de estudantes que, em algum momento, participaram de uma ou mais sessões. A participação na pesquisa não foi obrigatória, no entanto houve uma ajuda do professor da disciplina, incorporando as atividades desenvolvidas na pesquisa a sua avaliação, bonificando aqueles que realizassem as atividades propostas.

Como estratégia para a coleta de dados, as sessões foram filmadas e gravadas em áudio, cujo material foi transcrito e utilizado para a análise. Além disso, recolhemos todo o material desenvolvido pelos estudantes nas sessões e fora dela por meio das atividades 
propostas e estes também foram utilizados na análise. Diante dos dados coletados, foi possível analisar as relações pessoais dos estudantes do curso superior de tecnologia, na área de gestão e negócios, sobre as noções de juros simples e compostos submetidos a um PEP.

\section{Análise das sessões do PEP}

Como afirmamos anteriormente, a aplicação do PEP foi efetuada numa turma de Gestão Comercial em oito sessões, nas quais os estudantes sempre tiveram aula da disciplina Matemática Financeira em paralelo. Na noite em que se realizavam as sessões, nas primeiras duas horas, os estudantes assistiram à aula de Matemática Financeira e, na última hora, participaram da pesquisa. Acreditamos ser importante destacar tal situação, pois suas ações na pesquisa muitas vezes eram influenciadas pelo que se lembravam das aulas da disciplina.

Na primeira sessão, em que se apresentou a pesquisa, observamos que os estudantes já haviam visitado, durante as disciplinas, o setor juros simples e o tema porcentagem. Compareceram, no dia, 75 estudantes que aceitaram participar da pesquisa e no decorrer das outras sessões, agregaram-se novos participantes. Entretanto a não obrigatoriedade levou à desistência e problemas associados à disciplina Matemática Financeira (abandono do curso e faltas) fizeram com que nas sessões nunca estivessem os 90 estudantes.

Ainda na primeira sessão, apresentamos a questão que norteou nossa pesquisa: “ $Q_{0}$ : Como decidir o tipo de empréstimo para uma empresa?". Pedimos que os estudantes elaborassem individualmente uma resposta para essa questão e a entregassem numa folha de papel, tendo havido exposição de todas, por eles, ao final. Alguns estudantes individualmente foram expondo suas respostas e construímos uma lista parcial no quadro negro.

Na dinâmica de exposição das respostas, emergiu a dificuldade dos estudantes em participar da atividade. Poucos (10 estudantes no universo de 75) expuseram suas respostas, isso depois de o pesquisador fazer um discurso sobre a importância da participação. Sabemos que sendo a primeira sessão, os estudantes poderiam estar inibidos em participar, mas também enxergamos que não estavam preparados/acostumados a terem este tipo de responsabilidade, ou seja, buscar uma solução para o desafio didático proposto.

Tal situação remete diretamente à dialética individual-coletivo, em que no PEP "O sistema didático passa então da autonomia (individual, sob a direção de $Y$ ) para a construção de uma sinonímia (coletiva, em cooperação com Y)" (CHEVALLARD, 2009, p. 14-15, tradução nossa). Carecemos que os estudantes assumam a responsabilidade de cooperação no sistema didático, o que no primeiro momento mostra-se difícil em função do hábito. 
Comparamos o que havíamos descrito a priori com o que eles propunham. Algumas repostas $\mathrm{R}^{\diamond}$ haviam sido previamente supostas nos caminhos considerados na Figura 1, contudo é possível verificar que além de encontrarmos respostas não previstas, elas extrapolaram as noções habitualmente associadas ao domínio da Matemática Financeira, já que, por exemplo, foram citadas as noções: segmento da empresa, perfil da empresa, objetivo do empréstimo, carteira de clientes, benefício fiscal, plano de negócios, variação cambial, faturamento, ativos da empresa, planejamento etc.

Quando se trata de uma questão relacionada à Matemática Financeira com um público de gestão e de negócios, as noções não se resumem às que geralmente encontramos nos livros didáticos: taxas de juros, montante, período de capitalização, capital e tipo de capitalização. Houve respostas que apontavam para a importância de considerar outras informações para dar continuidade na busca por uma resposta, isto é, os dados indicam o caráter gerador da questão inicial $Q_{0}$; e a construção da resposta $R^{\bullet}$ não seria única no sentido de que teríamos respostas diferentes ao mesmo questionamento.

Ainda sobre as respostas fornecidas pelos estudantes, um primeiro passo é dado na dialética mídia-meio, quando buscamos respostas já validadas para compor o meio de estudo e pesquisa, mesmo que estas respostas sejam aquelas advindas da experiência dos estudantes.

Tomando como base os trabalhos que já experimentaram a organização didática PEP, pedimos que os estudantes formassem grupos de três ou quatro integrantes para discutir sobre a questão $Q_{0}$ e as respostas propostas anteriormente para, na sequência, elaborar uma resposta do grupo, pois na primeira exposição, houve uma grande diversidade de respostas, sendo necessário analisar as que estavam em acordo com a questão, as que poderiam ser dispensadas e as que já se inseriam em outras respostas.

Observamos que, apesar de estar programada a apresentação das respostas dos grupos para a primeira sessão, não foi possível fazê-la por escassez de tempo, o que ocorreu na segunda sessão. Foi um indício de que o tempo didático havia sido modificado, quando a responsabilidade pela busca da resposta ficou a cargo do estudante, pois mesmo com poucos estudantes expondo suas ideias, essa possibilidade de participação provocou uma breve discussão sobre os elementos que auxiliariam na busca pela resposta. Isso ficou ainda mais claro no desenvolvimento das outras sessões, pois sempre "faltava" tempo.

Na perspectiva de otimizar o tempo de aproveitamento da sessão, decidimos enviar um e-mail aos participantes antes do dia da sessão, explicitando qual era o planejamento de ações da segunda sessão. Mesmo com esta ação, as exposições sempre oportunizavam um meio de discussão das respostas escolhidas pelos grupos, o que interferia no tempo das ações planejadas. 
As ações planejadas para a segunda sessão foram: exposição dos critérios de avaliação das atividades, responder a um questionário, retomada da atividade realizada em grupo e ainda definição da divisão de responsabilidades no grupo: quem seria o expositor do trabalho a cada semana e quem ficaria encarregado de entregar relatórios semanais.

A exposição dos critérios de avaliação e informações sobre o questionário aplicado não é o foco de abordagem neste trabalho, mas podemos resumir que o modo como pretendíamos avaliar o trabalho foi baseado na responsabilidade dos participantes, na consulta a fontes externas como meios de fundamentar as respostas e na argumentação apresentada. Já o questionário serviu-nos para diagnosticar qual o perfil e quais as relações pessoais dos estudantes em relação aos juros simples e compostos antes de serem submetidos à aplicação do PEP.

Ainda na segunda sessão, os estudantes, em grupos, reuniram-se para discutir a resposta ao questionamento $Q_{0}$ do grupo. De onze grupos, três procederam à gravação de sua reunião, possibilitando observar que apenas listaram as variáveis para responder ao questionamento, ou seja, não traziam justificativa para as respostas propostas.

A característica da necessidade de justificar a resposta foi explicitada, quando apresentamos a pesquisa, porém, desde o primeiro momento, esse tipo de ação foi difícil de ser realizada, tornando-se uma restrição no desenvolvimento do PEP. Inferimos que o fato deveuse a dar mais ênfase à resposta do que ao estudo na busca pela resposta e ainda serem submetidos comumente a questionamentos que têm uma única resposta. Fica clara a força do contrato didático habitual, como podemos observar no extrato que segue de uma discussão:

Estudante 4: Aí ele não vai precisar pegar um empréstimo. A pergunta não tem lógica. O cara vai pegar um empréstimo sem saber qual o objetivo? Você entendeu? Para mim esta pergunta aqui ela não tem lógica. Para mim, a pergunta seria outra: Qual a necessidade de uma empresa tomar um empréstimo? Por quê? A pergunta seria outra. Justamente com o tipo de empréstimo você teria uma definição de para quê. Para melhorias, para suprir demanda, produção, compra, mercadoria, ampliação de espaço, para melhorar na logística...

Estudante 5: Não seria viável aquela parte lá. De taxas? É necessário?

Estudante 6: Não, agora é só isso. Na próxima aula, ele vai dar outros tópicos para a gente continuar falando.

(Áudio do diálogo entre estudantes de um mesmo grupo, 2017).

O estudante 4 esperava por perguntas mais específicas e o de $n^{\circ} 6$ já acreditava que forneceríamos caminhos a serem seguidos. Estas não são características recorrentes no desenvolvimento do PEP, pois o professor tem um papel de orientador e ocupa uma posição de igualdade com os estudantes na tomada de decisão dos caminhos. Em relação às perguntas mais específicas, com respostas diretas, e muitas vezes únicas, também é algo que pode aparecer no $\mathrm{PEP}$, mas a expectativa é que surjam ainda mais questionamentos com múltiplas respostas a 
depender das decisões tomadas para a construção da resposta $R^{\boldsymbol{\nu}}$.

Podemos considerar ainda, na fala do estudante 4, que ele tentou justificar a afirmação ao dizer que o questionamento não tinha lógica, propondo novos questionamentos, mostrando, mesmo que involuntariamente, a presença da dialética questão-resposta, ou seja, a busca pela resposta $R^{\boldsymbol{v}}$ deriva novos questionamentos e amplia o campo de estudo. Isso também valida o poder gerador da questão $\mathrm{Q}_{0}$ proposta e ainda mostra que os possíveis caminhos que havíamos verificado na análise a priori foram contemplados pelos estudantes.

Ainda sobre a segunda sessão, os estudantes continuaram discutindo suas respostas e alguns grupos chamaram o pesquisador para esclarecer dúvidas relacionadas à inserção ou não de possíveis respostas $R_{i}^{\diamond}$. Notou-se a dificuldade em justificar suas respostas e a característica do questionamento não ter apenas uma resposta. Sobre a inserção ou não de respostas $R_{i}^{{ }_{i}}$, tentamos mostrar que a decisão e a justificativa caberiam a eles. No que tange à dificuldade em justificar as respostas, ficou visível que os grupos continuavam listando apenas as respostas e novamente tentávamos questioná-los com o objetivo de mostrar a importância da justificativa. Além disso, quando tentavam justificar, apresentavam apenas exemplos ou consideravam algumas de suas experiências; não consultavam obras como livros, sítios da internet, enciclopédias online, entre outros. Segue o extrato de uma atividade:

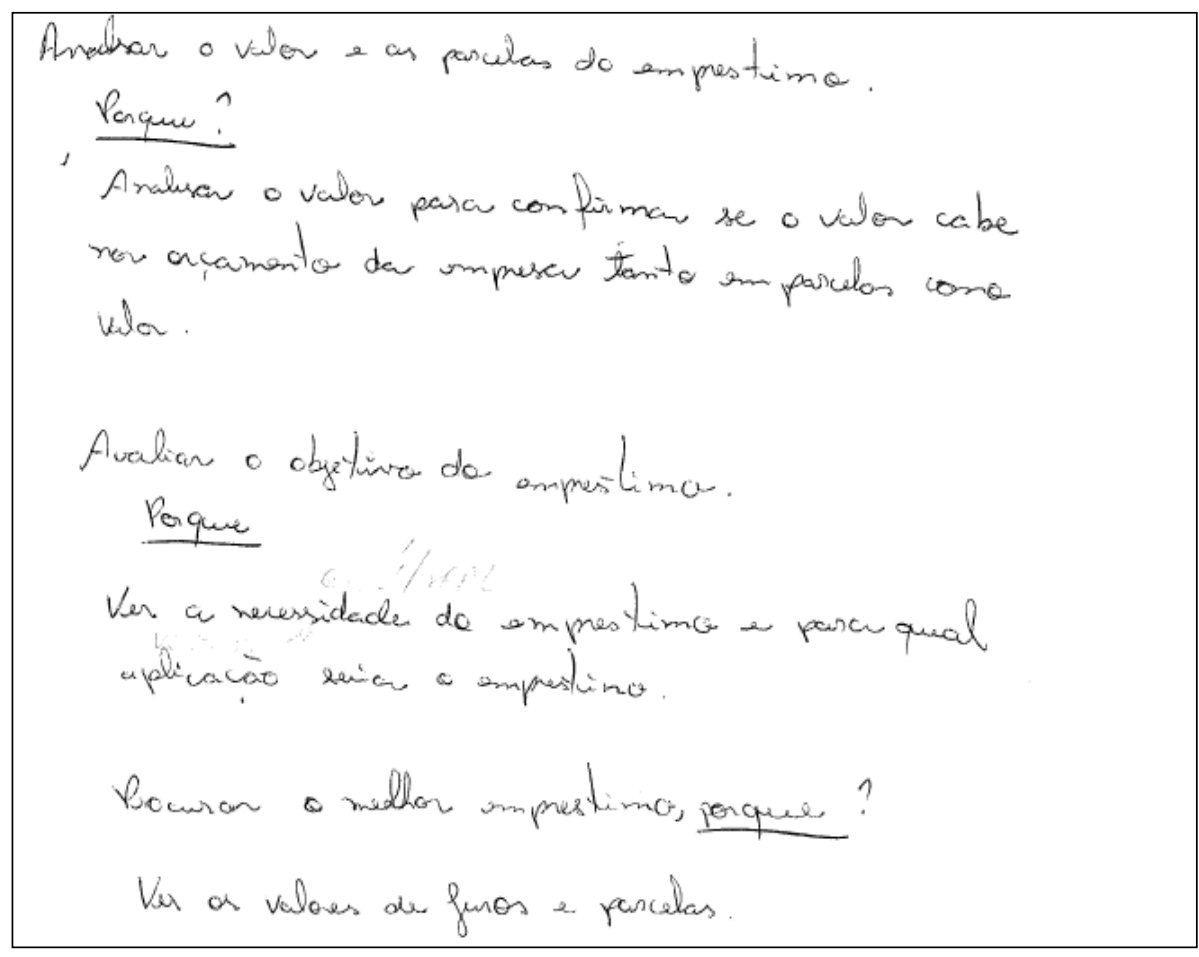

Figura 3 - Atividade da segunda sessão Fonte: O autor (2017)

Por não ter a questão uma única resposta, necessitou-se definir casos para que a busca pela resposta $R^{\boldsymbol{v}}$ evoluísse. Essa decisão foi tomada na terceira sessão, pois na segunda, 
novamente o tempo foi exíguo. Nas exposições ocorridas na terceira sessão, os grupos compreenderam a necessidade de definir qual o tipo de empresa estava se propondo ao empréstimo. Precisavam ter casos específicos norteando estudo e a pesquisa; logo, ficou definido que cada grupo trataria a resposta a partir de um caso escolhido pelo próprio grupo.

A sessão três foi dedicada exclusivamente à exposição das respostas dos grupos. $\mathrm{O}$ diálogo entre os grupos foi intenso no sentido de discordância de ideias, mas resultou na tomada de decisão anterior. Infere-se que, neste momento do diálogo, foi criado um meio de validação das respostas anteriormente coletadas pelos grupos; logo, a validação das respostas foi submetida a um meio, o que remete à dialética mídia-meio. Essa mídia ainda pode ser considerada frágil, pois os estudantes basearam suas respostas apenas nas experiências vivenciadas, não buscando outras obras.

Sobre as noções privilegiadas nas respostas dos grupos, podemos identificar que o foco continua em noções comumente não consideradas do domínio da Matemática Financeira. Além disso, utilizando o MER, considerado no início da pesquisa como critério de análise, verificamos que, ao final das três sessões, os estudantes ainda buscavam compreender as variáveis intra e extramatemáticas. Não significa que eles passaram por esta etapa e não voltarão mais para ela, pois em algum momento do estudo, talvez seja preciso novamente retornar a esta etapa para dar prosseguimento na construção da resposta $R^{\vee}$.

A quarta sessão foi destinada à exposição das respostas a partir dos casos estabelecidos pelos grupos. O relatório semanal de atividades foi entregue por doze grupos, sete no dia da quarta sessão e os outros cinco atrasados. Por falta de espaço suficiente para dissertar sobre todos os grupos, escolhemos dar ênfase no caso de um dos grupos. Este grupo (grupo 10), em nossa percepção, foi o que estava mais envolvido com a atividade. Supomos que seja em razão de a questão estar associada à realidade de um dos integrantes do grupo.

$\mathrm{Na}$ exposição do grupo 10, explicitou-se o cenário de estudo e pesquisa. O número ao lado do 10 denomina o estudante (Grupo 10, estudante 1 = 10_1):

Estudante 10_1: No caso, eu escolhi uma microempresa que existe no ramo de tapeçaria com apenas quatro funcionários. Uma empresa que tem uma rentabilidade de $R \$ 9.000,00$ por mês e de $R \$ 108.000,00$ anual. E a empresa está precisando de $R \$ 20.000,00$ de empréstimo.

[...]

Estudante 10_1: Fiz um empréstimo do BNDES (Banco Nacional de Desenvolvimento). Neste caso a taxa estava saindo em torno de 3\% para um empréstimo de $R \$ 20.000,00$. (o pesquisador escreve os dados no quadro).

Pesquisador: Você sabe informar se esta taxa incide ao mês ou anual?

Estudante 10_1: Ao mês. Ele financia até 100\% do valor proposto.

Pesquisador: A instituição bancária perguntou qual era o objetivo do empréstimo?

Estudante 10_1: Sim. Para melhorias na oficina e no maquinário. (o pesquisador escreve no quadro os dados) 
Pesquisador: Vocês têm alguma outra informação?

Estudante 10_1: Não. Só isto mesmo.

Pesquisador: A partir destes dados, o que você conseguiu de empréstimo?

Estudante 10_1: Então... eu fui pesquisar informações em outro banco. No BNDES, eu consegui a taxa de $3 \%$ para ser paga em 24 parcelas.

Pesquisador: Acredito que a aula do Professor Cido vai ajudar bastante para compreendermos esta situação que a colega trouxe. Vamos agora escrever no quadro as informações dos outros bancos. Quais foram os outros bancos Estudante 10_1?

Estudante 10_1: HSBC. Taxa de 2,2\%.

Estudante 10_2: Tivemos outros bancos também, professor. É o caso do banco Santander com a taxa de 2,56\%. Caixa Econômica Federal a 2,81\% e Itaú a 3,05\%.

Pesquisador: Estas taxas foram sugeridas para o seu prazo ou os bancos sugeriram os prazos para pagamento de acordo com as taxas praticadas?

Estudante 10_1: Os bancos te dão outras opções de prazos maiores. Porém, com a taxa diferenciada.

Pesquisador: Vamos refletir no prazo de acordo com as taxas oferecidas. Todos aceitaram sua proposta de empréstimo?

Estudante 10_1: Sim. $R \$ 20.000,00$.

(Exposição do grupo 10, 2017).

O referido professor Cido ministra a disciplina Matemática Financeira para essa turma.

Em relação ao que foi exposto pelo estudante no extrato anterior e o que continha no relatório entregue pelo grupo, podemos verificar que os estudantes assumiram a responsabilidade na busca pela resposta $R^{\vee}$ do questionamento $Q_{0}$. Isso evidencia a dialética individual-coletivo, na qual passamos do foco no professor y para um processo de cooperação entre os estudantes $X \mathrm{e}$ o professor (pesquisador) $y$, com ajuda de $y$ em relação à proposta de novas questões.

O compartilhamento de responsabilidade por parte do pesquisador também não se deu de maneira tão espontânea. Observa-se, pelo trecho anterior, que o pesquisador ainda traz, em suas ações, posturas intimamente ligadas à concentração da responsabilidade no professor, por exemplo, de expor as informações por meio do quadro negro e de propor questões para auxiliar na evolução da tarefa. A dificuldade de compartilhar a responsabilidade com os estudantes transpareceu durante todas as sessões, mas, ao final, os estudantes demonstraram em seus discursos que o pesquisador inseriu gestos didáticos visando sempre a que eles se posicionassem e valorizava a resposta dada por eles, incentivando a cooperação de todos.

O grupo 10, ainda na quarta sessão, expondo seu estudo, informou que havia eleito o banco $H S B C$ para fornecer o empréstimo. O pesquisador propôs novos questionamentos e, entre eles, o do valor da parcela do empréstimo. Contudo o grupo não dispunha dessa informação e o pesquisador indicou que os dados que tinham possibilitariam calcular o valor da parcela, uma vez que tal temática fora trabalhada na aula de Matemática Financeira no mesmo dia.

Pesquisador: O que posso perguntar para você é: Qual o valor da parcela?

Estudante 10_1: O valor da parcela eu não trouxe. O que eu tenho é o valor total dos juros, que são $R \$ 13.717,20$.

Pesquisador: Acredito que, com esta informação, tem como vocês descobrir as parcelas. Vamos 
relacionar o que vocês viram na aula de hoje com o Professor Cido. Vocês têm o quê?... (apontando para o valor presente, a taxa de juros e o prazo escritos no quadro negro). Vamos colocar as ideias no "lugar". O que isso aqui representa? (apontando para o valor do empréstimo)

Estudante 10_2: Valor presente.

Pesquisador: E isso aqui? (apontando para os juros)

Estudante 10_2: Isto é o juros.

Pesquisador: Tem como sabermos mais de alguma coisa com estas informações?

Estudante 10_1 e Estudante 10_2: Dois ponto vinte é a taxa.

Pesquisador: E qual o Valor Futuro?

Estudante 10_1: $R \$ 33.717,20$. O valor da prestação é $R \$ 1.404,88$.

(Exposição do grupo 10, 2017).

Os estudantes não conseguiram fazer a relação do que tinham estudado havia alguns minutos com a situação surgida na pesquisa, o que conduziu o professor Cido a intervir, pela primeira vez, na experimentação da pesquisa, mostrando como deveria ser feito. Essa intervenção reduziu a possibilidade de os estudantes continuarem as descobertas de como calcular o valor da prestação, evidenciando a força do contrato didático habitual.

Mesmo diante da ação do professor, tentamos mostrar a necessidade de compreender o cálculo da parcela em um empréstimo, o que foi reforçado a partir da exposição dos trabalhos dos outros grupos na sessão 4. Assim como o grupo 10, outros não sabiam quanto iriam pagar pelo empréstimo, desconheciam como calcular o valor da parcela. Então orientamos que, para a próxima sessão, os estudantes buscassem informações sobre o cálculo do valor da parcela na situação do empréstimo, considerando as informações que os grupos haviam exposto.

Antes do início da quinta sessão, um dos integrantes do grupo 10 procurou o pesquisador, pois não estava conseguindo compreender o porquê de os juros produzidos na multiplicação da quantidade das parcelas não ser igual ao produzido, quando ele aplicava a fórmula do montante dos juros compostos. Esta dúvida aconteceu com mais três grupos que experimentaram simular o cálculo da parcela em uma instituição bancária, conotando que os estudantes não haviam compreendido a dinâmica do cálculo do montante dos juros compostos. Além disso, eles mostraram ter dúvidas em tipos de tarefas que ajudavam a compreender a formação de uma parcela e a fórmula do montante dos juros compostos, a saber: resolver equações, operar com números racionais e fatorar expressões algébricas.

Esse contexto impactou no tempo didático. A quinta sessão resumiu-se a um estudo de dúvidas, o que impossibilitava o avanço na busca pela resposta $R^{\boldsymbol{}}$. Porém consideramos isso positivo. A dinâmica do PEP oportuniza a discussão de noções anteriores de forma conectada, o que valoriza o paradigma do questionamento do mundo.

Objetivando ajudar na compreensão do cálculo da parcela, tivemos na sexta e sétima sessões Atividades de Estudo e Pesquisa - AEP (anexo A), em que focamos questões próprias 
da disciplina Matemática para que os estudantes pudessem compreender que a fórmula do montante não era suficiente para o cálculo do valor da parcela de um empréstimo. Esta é uma característica que diferencia a AEP do PEP, enquanto a primeira é organização didática com viés disciplinar; a segunda não se resume a uma única disciplina na busca pela resposta $R^{\boldsymbol{\nu}}$.

Na aplicação da AEP, o grupo 10 prosseguiu seus estudos para compreender a formação dos juros no caso do empréstimo. Ao responder aos questionamentos da AEP, eles compreendiam que a fórmula do montante não se inseria no caso do empréstimo, pois a cada pagamento de uma parcela, a taxa de juros incidia sobre o valor restante. Essa dinâmica caracteriza o tema série uniforme de pagamentos no domínio da Matemática Financeira. Indicamos que eles precisavam buscar informações sobre este tema, o que auxiliaria na compreensão da formação da parcela e, consequentemente, nos juros de um empréstimo.

Analisando os gestos didáticos do grupo 10 até a sétima sessão, verificamos que os integrantes do grupo assumiram a responsabilidade do estudo e da pesquisa, formularam novos questionamentos a partir de suas dúvidas e estavam sempre buscando informações para enriquecer a validação da resposta proposta. Em relação à resposta $R^{\vee}$ construída pelo grupo, podemos considerar que ainda havia alguns caminhos a serem explicitados de acordo com as dificuldades encontradas pelo grupo, mas a escassez de tempo inviabilizou novas especulações. Entretanto também observamos que o meio $\mathrm{M}$ formado não se resumiu a informações dadas pelo pesquisador e que a validação das respostas esteve sempre em confronto com as obras consultadas, dando um caráter de investigação ao PEP.

A oitava sessão foi dedicada à avaliação por parte dos estudantes do que haviam experimentado com a aplicação de um PEP; logo, não cabe analisarmos. Todavia, vimos que o mais destacado pelos estudantes foi a mudança das responsabilidades no processo e o sentido que a atividade deu ao estudo das noções associadas ao domínio da Matemática Financeira.

\section{Conclusão e perspectivas futuras}

Feita a análise do PEP, chegamos a algumas conclusões sobre a relação pessoal dos estudantes com as noções do domínio da Matemática Financeira e sobre o desenvolvimento da organização didática PEP. Sobre este último, destacamos a dificuldade dos estudantes em considerar um ambiente cooperativo para a construção da resposta ao questionamento $Q_{0}$, principalmente nas primeiras sessões. A partir da terceira, foi possível observar mudanças. Inferimos que esse fato está intrinsecamente ligado ao contrato didático habitual a que eles foram submetidos, no qual a responsabilidade na condução do estudo é do professor. 
A aplicação do PEP também evidenciou que o tempo didático não é tão controlado, quando as responsabilidades são compartilhadas e as respostas não são apenas do professor. Foi possível observar que o tempo sempre era insuficiente diante da variedade de respostas e discussões geradas no compartilhamento das informações entre os grupos.

No que diz respeito à relação pessoal dos estudantes com as noções de juros simples e compostos submetidos ao PEP, verificamos que estas temáticas não foram o foco do estudo e da pesquisa por partes dos estudantes. Isso não é indicativo de que eles não se preocupam com as noções do domínio da Matemática Financeira; pelo contrário, o que acontece é uma mudança de tratamento das noções, que funcionam como ferramentas para a execução da tarefa. Além disso, para os estudantes, o estudo das noções do domínio da Matemática Financeira parece ter tido mais sentido do que quando estudadas fora da dinâmica do PEP.

Acreditamos ainda que a questão $Q_{0}$ ampliou a noção de juros compostos, quando trata as questões relacionadas ao pagamento postecipado e desmistifica a aplicação da fórmula do montante para todos os casos financeiros utilizando a mesma dinâmica de cálculo. Essa mistificação foi bastante recorrente entre os grupos participantes da pesquisa. Conjecturamos que este erro está associado ao paradigma de visita das obras, no qual as noções matemáticas são visitadas na escola com deferência e com a perda do sentido do porquê estarem lá. É comum encontrar em livros didáticos da Educação Básica atividades propostas para serem resolvidas com a fórmula do montante para a operação financeira de empréstimo.

Para finalizar, dentre vários questionamentos surgidos a partir do desenvolvimento desta pesquisa, destacamos um a que fizemos referência na análise e que diz respeito ao professor no desenvolvimento de um PEP. A experimentação do PEP desta pesquisa foi vivenciada pelo próprio pesquisador e, como comentamos na análise, este sentiu dificuldade em como gerenciar o compartilhamento das responsabilidades com os estudantes. É nessa perspectiva que consideramos questionamentos futuros: Como o professor compreende o compartilhamento da responsabilidade no processo de estudo e pesquisa? Quais as dificuldades encontradas ao compartilhar as responsabilidades? É possível que uma das responsabilidades dos estudantes seja gerenciar o tempo didático de busca pela resposta?

\section{Agradecimentos}

Agradecemos à CAPES pelo financiamento de bolsa, em particular da bolsa de doutorado sanduíche, que ajudou no desenvolvimento da pesquisa e, consequentemente, no 
desenvolvimento deste trabalho. Também agradecemos a ajuda da projeto MINECO/FEDER, EDU2015-69865-C3-1-R (Ministerio de Economía y Competitividad, Espanha).

\section{Referências}

BARQUERO, B.; BOSCH, M.; GASCÓN, J. Using Research and Study Courses for Teaching Mathematical Modelling at University Level, 2007. Disponível em: <http://www.mathematik.unidortmund.de/ erme/CERME5b/WG13.pdf>. Acesso em: 28 de junho de 2016.

BARQUERO, B.; BOSCH M.; GASCÓN J. Los recorridos de estudio e investigación y la modelización matemática en la enseñanza universitaria de las ciencias experimentales, 2011. Disponível em: <http://www.raco.cat/index.php/Ensenanza/article/view/247884>. Acesso em: 08 de março de 2015.

BARQUERO, B. et al. La prise en compte du collectif dans l'analyse de deux parcours d'étude et de recherche en ligne, 2016. Disponível em: <https://hal.archives-ouvertes.fr/hal-01323676>. Acesso em: 24 de fevereiro de 2017.

BOSCH, M. L'économie des Parcours d'Étude et de Recherche au Secondaire. Conferência. In: GUEUDET, G.; ALDON, G.; DOUAIRE, J.; TRGALOVA, J. (Eds). Apprendre, enseigner, se former en mathématiques: quels effets des ressources? Lyon: Insitut National de Recherche Pédagogique, 2010. p. $19-34$.

BOSCH, M.; GASCÓN, J. Fundamentación antropológica de las organizaciones didácticas: de los "talleres de prácticas matemáticas" a los "recorridos de estudio e investigación". In: BRONNER, A.; LARGUIER, M.; ARTAUD, M.; BOSCH, M.; CHEVALLARD, Y. ; CIRADE G.; LADAGE, C. (Eds.) Diffuser les mathématiques (et les autres savoirs) comme outils de connaissance et d'action. Montpellier: IUFM de l'Académie de Montpellier, 2010. p. 49 - 85.

BROUSSEAU, G. Théories des situations didactiques. 1.ed. Grenoble: La pensée Sauvage, 1998.

CHEVALLARD, Y. Organiser l'étude 1: Structures \& Fonctions, 2001. Disponível em: <http://yves.chevallard.free.fr/spip/spip/IMG/pdf/Organiser_1_etude_1.pdf>. Acesso em: 10 de fevereiro de 2016

CHEVALLARD, Y. Organiser l'étude 3: Ecologie et Regulation, 2002. Disponível em: <http://yves.chevallard.free.fr/spip/spip/IMG/pdf/Organiser_1_etude_3.pdf>. Acesso em: 24 de março de 2016.

CHEVALLARD, Y. Passé et présent de la théorie anthropologique du didactique, 2007. Disponível em: <http://yves.chevallard.free.fr/spip/spip/IMG/pdf/Passe_et_present_de_la_TAD2.pdf $>$. Acesso em: 27 de fevereiro de 2018.

CHEVALLARD, Y. Un concept en émergence: la dialectique des médias et des milieux, 2008. Disponível em: <http://yves.chevallard.free.fr/spip/spip/IMG/pdf/YC_-_Sem_nat_DDM__23_mars_2007.pdf >. Acesso em: 20 de abril de 2016.

CHEVALLARD, Y. La TAD face au professeur de mathématiques, 2009. Disponível em: $<$ http://yves.chevallard.free.fr/spip/spip/IMG/pdf/La_TAD_face_au_professeur_de_mathematiques.pd f>. Acesso em: 04 de outubro de 2016.

CHEVALLARD, Y. Didactique Fondamentale - Module 1: Leçons de didactique. Curso dado a Universidade de Provence, 2011. Disponível em:

<http://yves.chevallard.free.fr/spip/spip/IMG/pdf/DFM_2011-2012_Module_1_LD_.pdf>. Acesso em: 
30 de abril de 2015.

CHEVALLARD, Y. Praxeological Issues in the Development, Reception and Use of ATD, 2016. Disponível em: <http://www.atd-tad.org/wp-content/uploads/2016/03/Chevallard_TAD-

5_TexteCoference_EN.pdf $>$. Acesso em: 27 de fevereiro de 2018.

CHENEVEZ, O. Mobiliser les outils utiles à l'enquête : le cas de la démarche journalistique, 2008. Disponível em: <https://esup.espe-

bretagne.fr/efficacite_et_equite_en_education/programme/symposium_chevallard.pdf $>$. Acesso em: 02 de janeiro de 2018.

HAUSBERGER, T. Dimensions collaboratives et dialectique médias-milieux: un questionnement didactique autour d'une retranscription d'échanges sur un forum de mathématiques. In: MATHERON, Y.; GUEUDET, G.; CELI, V.; DEROUET, C.; FOREST, D.; KRYNSINSKA, M.; QUILIO, S.; ROGALSKI, M.; SIERRA, T. A.; TROUCHE, L.; WINSLOW, C.; BESNIER, S. (Org.). Enjeux et débats en didactique des mathématiques: 18 ème Ecole d'été de Didactique des Mathématiques. Brest : La Pensée Sauvage, 2016. p. 613 - 622.

KIDRON, I. et al. Context, milieu, and media-milieus dialectic: A case study on networking of AiC, TDS, and ATD. In: BIKNER-AHSBAHS A.; PREDIGER S. (Eds.). Networking of theories as a research practice in mathematics education. Cham: Springer, 2014. p. $153-177$.

LUCAS, C. Una posible «razón de ser» del cálculo diferencial elemental en el ámbito de la modelización funcional. 2015. 597 f. Tese (Doutorado em Técnicas Matemáticas Avançadas e suas Aplicações) - Departamento de Matemática Aplicada. Universidad de Vigo, España, 2015. Disponível em: <http://www.atd-tad.org/documentos/una-posible-razon-de-ser-del-calculo-diferencialelementalen-el-ambito-de-la-modelizacion-funcional/>. Acesso em 30 de dezembro de 2017.

\section{MATHERON, Y.; NOIRFALISE, R. Une recherche de la Commission inter-IREM (CII)} didactique soutenue par l'INRP: Dynamiser l'étude des mathématiques dans l'enseignement secondaire (collège et lycée) par la mise en place d'AER et de PER, 2007. Disponível em: <http ://educmath.ens-lyon.fr/Educmath/ressources/documents/cdamperes/matheron_noirfalise.pdf $>$. Acesso em: 27 de fevereiro de 2018.

RODRÍGUEZ, E.; BOSCH, M.; GASCÓN, J. An Anthropological Approach to Metacognition: the "Study and Research Courses". In: CERME, 5. 2007, Nicosie, Proceedings... Nicosie: Université de Chypre, 2007. p. 1798-1807. Disponível em: <http://www.mathematik.uni-dortmund.de/ erme/CERM E5b/WG11.pdf $>$. Acesso em: 27 de fevereiro de 2018.

RUIZ, N.; BOSCH, M.; GASCÓN, J. The functional algebraic modelling at Secondary level. In: CERME, 5. 2007, Nicosie, Proceedings... Nicosie: Université de Chypre, 2007. p. 2170-2179. Disponível em: <http://ermeweb.free.fr/CERME\%205/WG13/13_Ruiz.pdf>. Acesso em: 27 de fevereiro de 2018.

SERRANO, L.; BOSCH, M.; GASCÓN, J. “Cómo hacer una previsión de ventas”: propuesta de recorrido de estudio e investigación en un primer curso universitario de administración y dirección de empresas, 2007. Disponível em: <http://www.atd-tad.org/wp-content/uploads/2012/05/SerranoBos chGascon-CITAD-II-2010.pdf >. Acesso em: 02 de fevereiro de 2015.

SIERRA, T. Á. Lo matemático en el diseño y análisis de organizaciones didácticas: los sistemas de numeración y la medida de magnitudes. 2006. 478 f. Tese (Doutorado em Didática da Matemática) Universidad Complutense de Madrid, Facultad de Educación, Madrid, 2006.

Submetido em 31 de Março de 2018. Aprovado em 13 de Agosto de 2018. 


\section{Anexo}

\section{ORGANIZANDO AS INFORMAÇÕES}

Vamos nessa atividade organizar as informações que vocês pesquisaram para responder nossa questão principal: Como decidir o tipo de empréstimo para uma empresa?

Lembro que em aulas anteriores propusemos um novo questionamento que auxilia na busca de nossa resposta. O questionamento lançado foi: Como explicar os juros de um empréstimo?

A partir deste questionamento, sugerimos que, para buscarmos a resposta, você responda às atividades a seguir que têm o objetivo de organizar as informações coletadas por sua empresa.

a) Qual o valor do empréstimo da sua empresa?

b) Qual a taxa de juros escolhida para o empréstimo de sua empresa?

c) Qual o prazo para pagamento concedido e escolhido pela sua empresa?

d) Foi cobrada alguma outra taxa ou comissão adicional, além da taxa de juros utilizada pelo empréstimo?

e) Qual foi o custo efetivo total financiado no seu empréstimo?

f) Qual o valor da parcela?

g) Quais os juros cobrados pelo banco na situação simulada?

h) Calcule os juros do seu empréstimo utilizando a fórmula de cálculo de juros que você já conhece. Explique como você calculou.

i) Os juros das letras $g$ e $h$ foram iguais? Explique sua resposta.

\section{COMPREENDENDO A FÓRMULA DE JUROS COMPOSTOS}

\section{COMPREENDENDO A FÓRMULA DOS JUROS COMPOSTOS}

Diante da constatação de que os juros informados pelo banco diferem dos juros quando utilizamos a fórmula dos juros compostos, vamos tentar compreender a dinâmica de incidência dos juros compostos. atividades.

Importante: Utilizem as informações do seu empréstimo para resolver as

a) Utilizando as noções de juros compostos, qual o juro do valor emprestado depois de um mês? E dois meses?

b) Qual o juro após três meses? E quatro meses?

c) Existe alguma dificuldade em calcular quando o número de meses aumenta? Explique.

d) Alguma operação é repetida no cálculo dos juros dos meses? Caso sim, qual?

e) O que podemos fazer para diminuirmos os cálculos?

f) Utilizando as respostas anteriores, explique de maneira objetiva como se calculam os juros compostos, justificando as suas ideias. 